\title{
MEASURING AUTOMATION AND INTEGRATION IN THE CONSTRUCTION INDUSTRY
}

\author{
James T. O'Connor, Mark E. Kumashiro, and Keith A. Welch \\ University of Texas at Austin \\ jtoconnor@mail.utexas.edu
}

\begin{abstract}
Project work process automation and integration technologies and advancements are emerging rapidly, and yet fragmented, limited in functionality, and not yet cost-beneficial in many areas. The construction industry's application of these advancements varies widely and is not well understood. This paper proposes a data gathering process and summary metrics that can be used to characterize industry levels of application of these systems and to better understand barriers to advancement and needs for further advancement.
\end{abstract}

Keywords: automation, integration, metrics, construction technologies

\section{INTRODUCTION}

construction industry with respect to task automation and the manner of task-to-task integration. This metric will also be useful in tracking industry automation and integration advancements over time as well as establishing a relationship between technology use and overall project performance.

The A/E/C industry is highly competitive. Thus, there is a strong motivation to develop and implement technologies that immediately bring about reduced cost, shortened delivery times, or other forms of value to clients. Conversely, there is a strong motivation to avoid technologies whose benefits are insufficient to justify the cost of the technology or whose benefits are unclear.

To a great extent, competition among technology suppliers and end-users drives the development and implementation of technologies. However, in many cases, there is an inadequate decision framework for the development and implementation of technology. This is especially true with regard to the cost and schedule impacts of technology. Development of an A\&I metric may highlight areas for improvement. When coupled with performance metrics the A\&I metric may also shed light on potential project impacts of technology use.

The A\&I metric is developed from project-based survey data. Each survey is intended to gauge the use of A\&I technologies on a single project and for a single company. With the survey data, various indices can be developed, representing technology use at the project, sector, and industry levels. A diversity of project types and sizes are being studied in order to yield a A\&I metrics that are representative of the industry. Projects are selected from the
The objective of this study is to develop a metric and related procedures useful for characterizing the

industrial, infrastructure, and building sectors. Data source company types include owners, contractors, supplier/fabricators, and subcontractors. In addition, survey data is being collected for both "advanced" and "typical" projects (relative to their application of A\&I technologies).

Data collection and analysis will be an ongoing process. One of the objectives of this research is to track A\&I advancements over time. Thus, it will be necessary to conduct the study over a period of several years with results reported annually.

\section{AUTOMATION AND INTEGRATION IN THE CONSTRUCTION INDUSTRY}

In discussing A\&I technologies, it useful to have a working definition of both automation and integration. For the purposes of this research automation is defined as a supplemental system or method in which autonomous or semi-autonomous equipment or information systems are used to supplement or replace human effort. It is useful to recognize two different types of automation -- that employed in the physical execution of tasks, such as site preparation or equipment installation, and that employed in creating and/or processing information. The first is inherently primarily mechanical, while the second is primarily electronic in nature. In this research, both types are considered.

Integration is the act of unifying otherwise separate parts. Two questions arise from this definition: 1) what parts are to be integrated? and 2) what is the mode of "integration"? Fergusson and Teicholz 
answer the first question through a tripartite definition of integration [1]. According to these researchers, integration can be inter-disciplinary such as the link between mechanical pipe routing and the structural system layout. It could be interorganizational such as the link between design changes and the builder's short-run schedule. It may even be a link across time such as lessons-learned following a major heavy lift that are subsequently used to improve future projects.

As for the mode of integration, for the purposes of this research, integration is defined as the electronic means by which discrete tasks are linked together (the link itself is referred to in this research as an integration link). This type of integration often exists in tandem with electronic or mechanical tools that enhance task automation.

There are numerous examples of technologies that support automation and integration in the $A / E / C$ industry. It is not the intent of this research to provide an exhaustive description of these technologies; rather, it is beneficial only to provide a technological context for abstract concepts of automation and integration. To this end, a listing of example technologies is shown in Table 1.

\section{PREVIOUS RESEARCH ON METRICS}

Research on the impacts of technology use have yielded mixed results. A 1989 study by Choi \& Ibbs [2] concludes that "computerization in the design office has not reduced total engineering costs significantly, although the home office engineering hours have been reduced by approximately $26 \%$ recently, the Construction Industry Institute has been conducting research on the use of key technologies on CIl members' construction projects. The CII Benchmarking and Metrics Database contains information on the use of design/ information technologies, such as integrated databases, bar-coding, 3D CAD, and electronic data interchange (EDI) for over 400 projects [6]. Project performance data has also been obtained for these projects, although the results pertaining specifically to these technologies are only now appearing.

\section{THE CASE FOR ADDITIONAL RESEARCH}

The previous research discussed thus far sets the stage for additional survey research with the following characteristics: during the past five years." Choi and lbbs concluded that the direct cost benefits of using computers were offset by additional costs related to their implementation. On the other hand, a 1995 report by Griffis, Hogan, and $\mathrm{Li} \mathrm{[3]} \mathrm{concludes} \mathrm{that} \mathrm{projects}$ that use 3D models experienced:

- $5 \%$ reduction in cost growth

- $4 \%$ reduction in schedule slip

- $65 \%$ reduction in rework

when compared to projects that used traditional design and construction methods. These results were based on a study of fifty-five CII companies and their use of 3D CAD in the design and construction phases of a project.

Research by Back uses a process model to illustrate quantitative impacts of process changes (some perhaps involving the use of technology) for both bulk materials management [4] and the delivery of a capital facility [5]. With regard to the 1994 study, Back concluded that intra-organizational integration resulted in a cycle time reduction of $38 \%$ over a nonintegrated bulk materials process. As expected, inter-organizational integration among project yielded even better results: a cycle time reduction of approximately $48 \%$. When process reengineering accompanied the implementation of EDI and bar code technologies, time and cost benefits approached 50\% [4]. On the other hand, Back's 1997 study showed the difficulty in demonstrating significant project cost and schedule benefits from any single application of technology [5].

In a 1993 study, Fergusson and Teicholz established a strong correlation between facility quality and integration [1]. This study included results from 17 industrial projects, and followed a thorough exercise in defining integration and quality metrics. More

- Development of a metric whose value can be taken to represent the state of the industry -- for all industry sectors and usefulo over an extended period of time. Previous research on A\&I metrics has focused primarily on industrial projects. It would certainly be useful to acquire a broader understanding of the industry by including all industry sectors. Since the industry is so varied, the amount of data required to represent it is substantial. Therefore, it is essential to have a survey tool that is: 1) general enough to be applicable to all sectors, and 2) concise enough to permit useful detailed analyses and interpretation of findings. In addition, it is useful to track this data over an extended period of time, observing changes as technologies are introduced or mature. Therefore, the survey tool should be designed in such a way as to be relevant for a period of several years prior to any revision. 
- Measurement of automation and integration for the entire project life cycle: In section 2, definitions of automation and integration were proposed. Previous research has provided assessments of automation [7] and integration [1] independent of one another. However, the concepts of automation and integration, while distinct, are very much interrelated. Thus, it will be useful to develop a measure that encompasses both concepts. Furthermore, it is important to recognize the process life-cycle aspects of automation and integration. Thus, any new research should consider all phases of the construction project, including facility operations and maintenance.

- The research effort should be project-focused: Focusing on specific projects allows technology "inputs" to be linked to overall project performance "outputs". The CII benchmarking and metrics efforts are the most profound example of "project-focused" data collection. When providing data to $\mathrm{Cll}$, companies are asked to furnish extensive cost, schedule, and safety data for specific projects. In addition, these companies provide information on the use of CII best practices, such as the use of design and information technologies discussed earlier.

- The development of an index that is not dependent on specific technologies; but rather on generic tasks that must be completed in the course of a project. Much previous research has focused on the use of specific technologies; how-ever, these technologies can become out-dated quickly. One advantage of measuring A\&I by task is the relative stability of the mix of tasks required to complete a project. For example, if one wished to measure automation in the execution of a building project, one might first start with a list of tasks:

- Mobilize

- Prepare site

- Lay foundation

- Erect steel structure

- Place concrete flooring, etc.

Short of a some major change, these tasks will likely remain relatively constant over time. However, one could make a judgment on the automation of these particular tasks, and with the advent of new construction technologies, actually observe changes in the level of automation used to execute these tasks over time.

- Characterization of "typical" as well as "advanced" projects. In completing a survey of technology use, the respondent company is likely to select "flagship" projects, those projects that place the participating company in the best possible light. From a research standpoint, such projects are of interest; however, it is also beneficial to understand the state of the industry "on average."

\section{DEVELOPMENT OF A SURVEY TOOL}

The survey is based on a list of 68 automation tasks and integration links covering six project phases: Front End (FE), Detailed Design (DD), Procurement $(\mathrm{PR})$, Construction Management (CM), Construction Execution (CE), and Operations \& Maintenance (OM). The tasks and integration links were selected on the basis of several criteria. First, the item has to have enough potential to impact project success to warrant its assessment. Each item also had to have sufficient potential to be automated. Each task and link also had to be applicable to a wide spectrum of project types and industry sectors to ensure comparability of findings. Finally, the task or link had to be reasonably specific so as to avoid ambiguous responses and possible misinterpretations.

An excerpt taken from the Front End portion of survey is shown in Figure 1. On this survey, the "Degree of Technology Use" relates to the level of A\&I of the automation task or integration link in question. Level 1 corresponds to "no electronic tools -or- commonly used electronic tools"; level 2 corresponds to "specialized, stand-alone electronic tools"; and level 3 corresponds to "integrated electronic tools." Respondents are asked to provide their judgment regarding the degree of A\&I technology use for each of the tasks/integration links on a given project.

In addition to characterizing the level of automation and integration, the survey is also used to conduct project performance assessments. The approach employed is based on previous work by $\mathrm{O}^{\prime}$ Connor \& McLeod [8] and includes assessments of cost performance (both total installed cost and operating costs), schedule performance, and safety. These assessments are generally considered fundamental measures of a project's ultimate success.

In addition to these, another assessment was developed specificially for this survey and is entitled "stakeholder success." This performance measure is intended to ensure that project success did not come at the extreme expense of a particular project stakeholder.

Finally, the survey contains provisions for classifying the project in terms of 1) technological sophistication (typical vs. advanced), 2) industry sector, 3) subsector, 4) project nature (green-field vs. renovation/expansion), 5) project size. 6) company type, and 7) company size. The classification schema is used to establish the representativeness of 
the data sample and to enable categorical analysis and reporting of findings.

\section{A\&I METRICS CALCULATIONS}

The data returned from the surveys are being used to test the following research hypotheses:

1) The use of A\&I technologies is expected to be greater for the following:

- Industrial sector (as opposed to the infrastructure \& building sectors)

- Advanced projects vs. typical projects

- Larger projects (in terms of total installed costs)

- New vs. renovations or expansions

2) The uses of A\&I technologies are increasing annually in all industry sectors.

3) The use of A\&I technologies bears a positive correlation with project cost, schedule, and safety performance (i.e. cost performance improves with the use of A\&I technologies, etc.)

4) The use of A\&I technologies bears a positive correlation with the success of project stakeholders.

Automation and integration indices are being developed in order to test these hypotheses. The number of index types defined in this research is partly driven by the need to characterize the use of technology both for the project life cycle as well as for individual phases. In addition, it is necessary to characterize the use of technology at various levels, including project, sector, and industry levels.

Because surveys are completed by a single participant, such as an owner or contractor, data may be provided only for certain phases of the project's life cycle (which encompasses a total of six phases). Thus, for each project, a series of so-called project phase A\&I indices I'FP are defined. There may be anywhere from one to six values for l' $\mathrm{F}$, corresponding to the phases for which data is available.

To describe the use of technology at the sector level, values of I'Fe (for a specific phase) are combined to create the Sector Phase A\&I Index, $I_{F S}$. Finally, to describe the use of technology at the industry level, values of $\mathrm{I}_{1: \mathrm{S}}$ are combined to form the Industry Phase A\&I Index, $\mathrm{I}_{\mathrm{F}}$.

Life cycle indices are calculated by adding phase indices at each level. For example, the Project A\&I Ratio is essentially the the sum of individual Project Phase A\&I Indices (returned data only). Likewise, the Sector A\&I Index, $I_{S}$, is the sum of individual Sector Phase A\&I Indices. Finally, the Industry A\&I index $I_{1}$ is the sum of Industry Phase A\&I Indices $I_{F}$. Figure 2 illustrates the construction of a Sector A\&I
Index from individual project data while Figure 3 summarizes various $A \& I$ indices and variables.

The number of index types is also driven by the need to characterize the use of technology at three different levels. At the project level, the values for I'P are combined to create a project A\&I index, IP. For a given sector, project A\&I indices are combined to determine the sector A\&I index (see Figure 2). Finally, sector A\&I indices can be combined to form an industry $A \& I$ index for the overall $A / E / C$ industry. A weighting scheme may be used to differentiate among tasks and links based on their relative importance.

There are a number of criteria upon which a task weights $\mathbf{w}_{\mathrm{r}}$ and/or phase weights $\mathbf{w}_{\mathrm{r}}$ may be based, including 1) relative "value-added" to the project from the task or integration link automation, 2) relative "cost-influence" attributed to the task or integration link, 3) relative cost of executing the task or integration link, and 4) relative "cost commitment" incurred to enable the task or integration link. These weights are shown applied to their respective variables in Table 3 .

\section{CONCLUSIONS}

The A\&I indices developed in this report may be useful in characterizing levels of task automation and integration within specific projects, industry sectors, and the construction industry at large. In addition. project level A\&I indices, when coupled with performance metrics (i.e. cost, schedule, safety, and stakeholder success), can be used to establish an empirical relationship between technology inputs and performance outputs. Such information can be used as a foundation for subsequent studies which may address barriers to advancement, base technology priorities, and other needs for research.

\section{REFERENCES}

[1] Fergusson, K. J. and Teicholz. P. M. (1993). Impact of Integration on Industrial Facility Quality. Department of Civil Engineering dissertation. Stanford University

[2] Choi, K. C. and Ibbs, C. W. (1989). Cost Effectiveness of Computerization in Design and Construction. Construction Industry Institute Source Document 50.

[3] Griffis, F. H.; Hogan, D. B.; Li, W. (1995). An Analysist of the Impacts of Using Three Dimensional Computer Models in the Management of Construction. The Construction Industry Institute Research Report 106-11. 
[4] Back. W. E. (1994). Quantifying Benefits of Electronic Technology Applied to Bulk Materials Management. Report to The Construction Industry Action Group.

[5] Back, W. E. Texas A\&M University, College Station, Texas. Interview, 21 August 1997.

[6] Benchmarking and Metrics Data Report 1997. The Construction Industry Institute, Document BMM 97-2
[7] Tucker, R. L.; Peterson, C.: Meyer, I.: Simonson, T. (1990). A Methodology for Identifying Automation Opportunities in Industrial Construction. Construction Industry Institute Source Document 56.

[8] O'Connor, James T., and McLeod. J. S. (1999). Planning for Startup: Analysis of the Planning Model and Other Success Factors. Research Report 121-3. Construction Industry Institute, Austin. TX.. 1999.

Table 1. Technologies in Support of Automation and Integration

\begin{tabular}{|c|c|}
\hline Technology Genres & Examples \\
\hline Hardware & $\begin{array}{l}\text { Client-server architecture } \\
\text { Data storage (e.g. magnetic, optical) } \\
\text { Wireless communication } \\
\text { Robotics } \\
\text { Bar coding } \\
\text { Radio frequency tagging }\end{array}$ \\
\hline Software \& applications & $\begin{array}{l}\text { Computer aided drafting and design (CADD) } \\
\text { Cost estimating } \\
\text { Schedule development } \\
\text { Specifications development } \\
\text { Enterprise Resource Planning (ERP) }\end{array}$ \\
\hline Standards and protocols & $\begin{array}{l}\text { Data exchange standards (e.g. EDI, STEP, IFC) } \\
\text { Internet/intranet }\end{array}$ \\
\hline Databases & Integrated databases \\
\hline
\end{tabular}

Figure 1. Excerpt from I\&A Metrics Survey, Front End Phase

\begin{tabular}{|c|c|c|c|c|c|c|}
\hline \multirow{2}{*}{ ID } & \multicolumn{2}{|c|}{ Task } & \multicolumn{5}{|c|}{ Degree of Technology Use } \\
\cline { 3 - 7 } & & $\begin{array}{c}\text { Don't } \\
\text { Know }\end{array}$ & 1 & 2 & 3 & N/A \\
\hline 1.01 & $\begin{array}{l}\text { Conduct market analysis or } \\
\text { need analysis for a new facility }\end{array}$ & $\square$ & $\square$ & $\square$ & $\square$ & $\square$ \\
\hline 1.02 & $\begin{array}{l}\text { Develop, evaluate, and refine } \\
\text { the project's scope of work }\end{array}$ & $\square$ & $\square$ & $\square$ & $\square$ & $\square$ \\
\hline 1.03 & $\begin{array}{l}\text { Diagram the manufacturing } \\
\text { process -or- the user's } \\
\text { processes (bubble diagram) }\end{array}$ & $\square$ & $\square$ & $\square$ & $\square$ & $\square$ \\
\hline
\end{tabular}

: Continued 


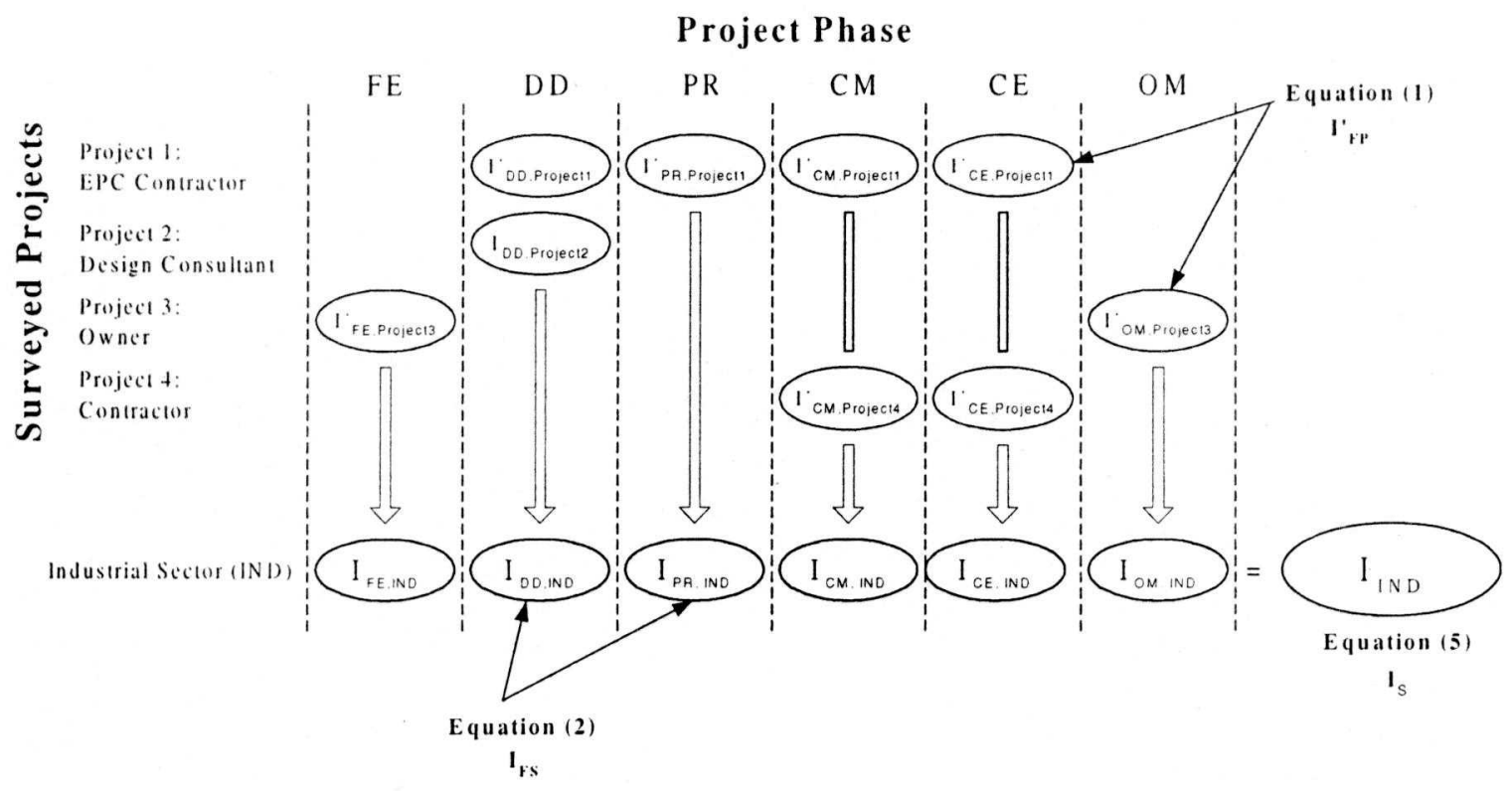

Figure 2. Calculating the Sector A\&I Index $I_{S}$ from a Sample of Four Projects

Figure 3. Summary of Important A\&I Metrics

\begin{tabular}{|c|c|c|}
\hline & Single Phase & Life Cycle \\
\hline 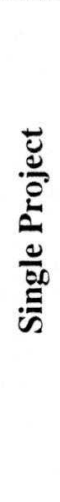 & 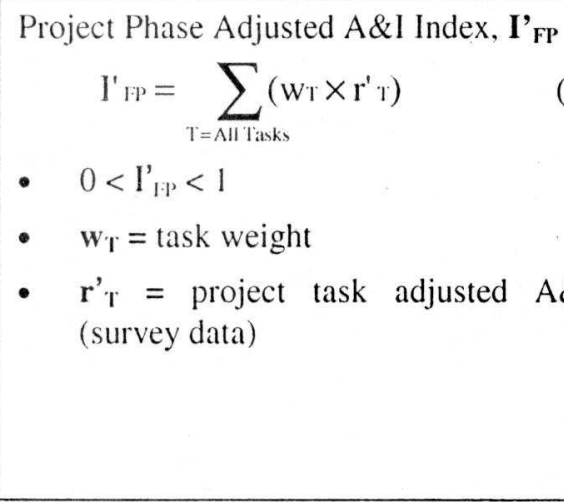 & 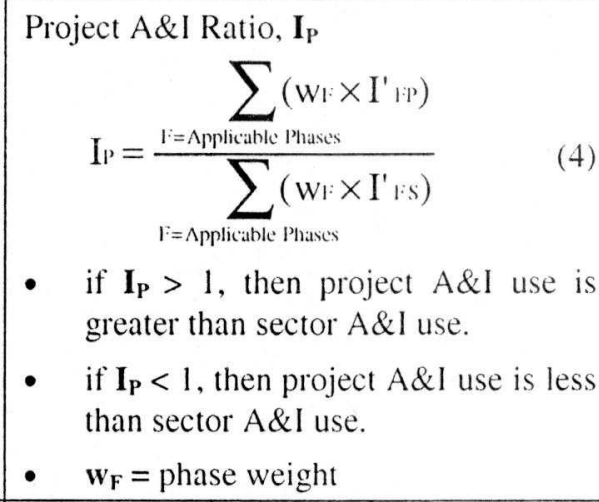 \\
\hline 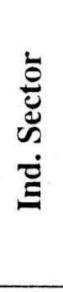 & 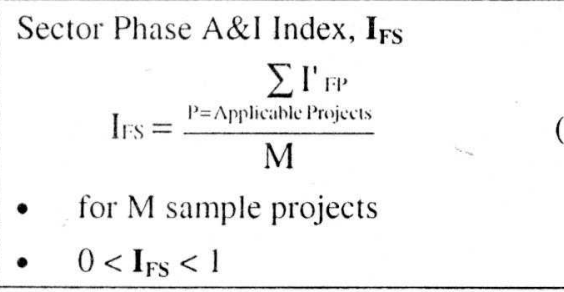 & 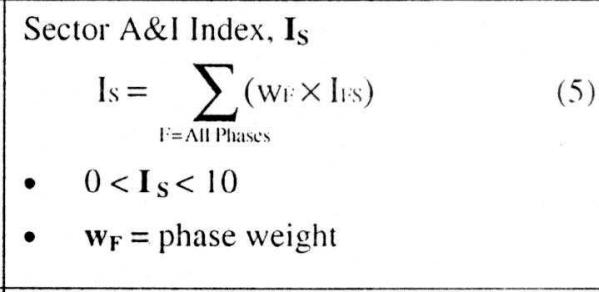 \\
\hline 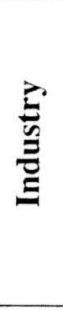 & 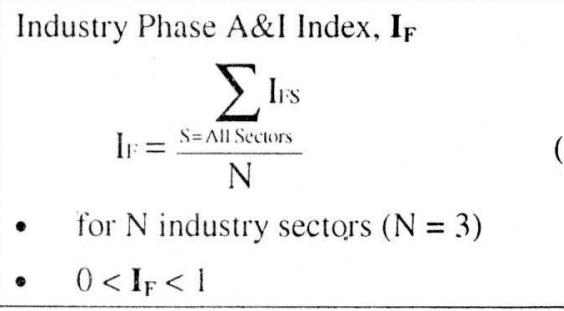 & 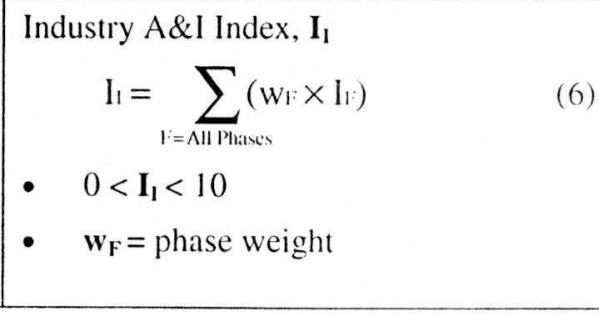 \\
\hline
\end{tabular}

